\title{
Effectiveness of the Barangay Disaster Risk Reduction and Management Committees (BDRRMCs) in Flood-Prone Barangays in Cabanatuan City, Philippines
}

\author{
Olive Chester Cuya-Antonio' ${ }^{1}$, Harron Dave P. Antonioº \\ ${ }^{1}$ City Disaster Risk Reduction and Management Department, Local Government of Cabanatuan, Cabanatuan City, Philippines \\ ${ }^{2}$ Department of Education Division of Cabanatuan City, Cabanatuan City, Philippines \\ Email: ocmcuya@yahoo.com, harrondave25@gmail.com
}

How to cite this paper: Cuya-Antonio, O.C. and Antonio, H.D.P. (2017) Effectiveness of the Barangay Disaster Risk Reduction and Management Committees (BDRRMCs) in Flood-Prone Barangays in Cabanatuan City, Philippines. Open Access Library Journal, 4: e3635.

https://doi.org/10.4236/oalib.1103635

Received: April 25, 2017

Accepted: July 8, 2017

Published: July 11, 2017

Copyright $\odot 2017$ by authors and Open Access Library Inc.

This work is licensed under the Creative Commons Attribution International License (CC BY 4.0).

http://creativecommons.org/licenses/by/4.0/

C) (i) Open Access

\begin{abstract}
This paper measured the organizational effectiveness of the Barangay Disaster Risk Reduction and Management Committees (BDRRMCs). It focused on the flood-prone barangays of Cabanatuan City, Philippines. The study used the Goal Model of Organizational Theory to measure the effectiveness of BDRRMCs. The effectiveness of BDRRMCs was measured against the goals and objectives of Republic Act 10121 also known as Philippines Disaster Risk Reduction and Management (DRRM) Act. The study used as a research tool the Checklist of Disaster Preparedness divided into four thematic areas namely; a) Disaster Prevention and Mitigation, b) Disaster Preparedness, c) Disaster Response, and d) Disaster Rehabilitation and Recovery. The resulting scores were described by the use of Disaster Preparedness Effectiveness Index. The study showed the need for periodic evaluation of the effectiveness of Barangay Disaster Risk Reduction and Management Committees (DRRMCs) and to set the standard of performance not only for the purpose of policy evaluation but also for measuring community involvement in disaster risk reduction.
\end{abstract}

\section{Subject Areas}

Politics

\section{Keywords}

Organizational Effectiveness, Disaster Risk Reduction and Management, Flood Prone Barangays, Organizational Evaluation 


\section{Introduction}

The Philippines is exposed to disasters and hazards because of its geography and geology [1]. It has been ranked third $\left(3^{\text {rd }}\right)$ among 173 countries in terms of exposure to hazards, such as typhoon, earthquake, flooding, landslide, volcanic eruption, and tsunami, according to the World Risk Index 2012 released by the United Nations International Strategy for Disaster Reduction (UNISDR).

On the R.A. 10121 Orientation Seminar conducted by the Office of Civil Defense, it has been presented that the Philippines' location along the Pacific Typhoon Belt made it prone to typhoon or hydrometeorological hazards. Based on the 2002 to 2012 data of the National Disaster Risk Reduction and Management Council (NDRRMC), the country experiences an average of twenty (20) typhoons a year, and $50 \%$ of it have damaging effects to lives and properties. At the same time, Philippines is also situated along the Pacific Ring of Fire that made it susceptible to earthquake and volcanic eruptions. These risks made the Philippine Disaster Management System to undergo a paradigm shift. From Presidential Decree 1566 to Republic Act 10121, from reactive to pro-active, from top-down and centralized management to bottom-up and participatory disaster risk reduction process.

Republic Act 10121, also known as the Philippines Disaster Risk Reduction and Management (DRRM) Act of 2010, is an Act focusing on strengthening the Philippine Disaster Risk Reduction and Management System [2]. Through this Act, the National DRRM Framework (NDRRMF) and National DRRM Plan (NDRRMP) were developed. Both the NDRRMF and NDRRMP foresee a country which has "safer, adaptive and disaster-resilient Filipino communities toward sustainable development". Together with the paradigm shift is the creation of the four thematic areas namely; a) Disaster Prevention and Mitigation, b) Disaster Preparedness, c) Disaster Response, and d) Disaster Rehabilitation and Recovery. Each area has long term goals and activities which will lead to the attainment of overall vision in DRRM. According to the NDRRMF, resources invested in the four thematic areas must prioritize disaster prevention and mitigation, disaster preparedness and climate change adaptation to be more effective in attaining its goal and objectives [3]. All of these were cascaded from national government to the barangay, the smallest political unit in the archipelago; and the nearest to the people in the localities serving as the primary planning and implementing unit of government programs, projects and activities [4]. As the political unit in the grassroots level, the Barangay Disaster Risk Reduction and Management Committee (BDRRMC) was mandated to implement RA 10121 (Sec. $12(\mathrm{a}))$.

Flooding is the primary hazard in Cabanatuan City. Despite the importance of reducing risk during manmade or natural made calamities, there is an observable gap in knowledge on how to measure the effectiveness of government unit in-charged of lessening the impact of disasters. At present, there is no standard tool to measure their effectiveness in the performance of functions. On the contrary, programs intended to measure the performance of the entire Local Gov- 
ernment Unit is well in placed. The Seal of Good Governance and the "Gawad Kalasag" are programs to measure performance of the LGU.

The SGLG was implemented by the Department of Interior and Local Government (DILG). It is an improvement of the Seal of Good Housekeeping that was launched on 2010, and integrated with the Seal of Disaster Preparedness that was released on 2012. The SGLG recognizes good performance of the LGUs, not only on financial housekeeping, but also on areas that directly benefit the people, including disaster preparedness [5]. While Gawad KALASAG (Kalamidad at Sakuna Labanan, Sariling Galing ang Kaligtasan) was implemented by the National Disaster Risk Reduction and Management Council (NDRRMC) through the Office of Civil Defense (OCD). It is a Search for Excellence in DRRM and Humanitarian Assistance, which recognizes exceptional contributions of DRRM practitioners in strengthening the resilience and adaptive capacities of nations and communities on disaster risks [6].

These national programs have their own limitations. They cannot measure the effectiveness of the Disaster Risk Reduction Management System at the Barangay level. Thus, the study is designed to fill the Gap in terms of performance evaluation at the barangay level. This would in turn assess the effectiveness of the policies enacted by the national and the effectiveness of its implementation in the grassroots level.

Performance measurement and program evaluation have been used and is essential for a more efficient, effective and accountable public sector [7]. Thus, an assessment at the barangay level is vital in the performance management of the local governments. Either way, according to Walker and Andrews (2013) a focus on service-delivery is important in the local government because local government represents the public face of the state and is where citizens experience of government is derived on a day-to-day basis [8].

\section{Objectives of the Study}

The main objective of the study is to measure the organizational effectiveness of the BDRRMCs of the flood-prone barangays in Cabanatuan City based on Disaster Prevention and Mitigation, Disaster Preparedness, Disaster Response, and Disaster Rehabilitation and Recovery.

The study is aimed at measuring the organizational effectiveness of the flood prone barangays in Cabanatuan City, Philippines along the areas of:

1) Disaster Prevention and Mitigation using as parameters:
a) Risk Assessment
b) Plans, Policies, and Budget
c) Early Warning System
d) Risk Financing
e) Environmental Management
f) Infrastructure Resilience

2) Disaster Preparedness in terms of:

a) Presence of a functional Barangay Development Council (BDC)

b) Presence of an institutionalized Barangay DRRM Committee 
c) Approved Plans

d) Capacity development activities conducted:

e) Partnership Mechanisms

3) Disaster Response;

4) Disaster Rehabilitation and Recovery;

5) The overall organizational effectiveness of the flood-prone barangays measured based on the four thematic areas of disaster risk reduction management.

6) To propose policy recommendation.

\section{Research Methodology}

\section{Study Locale}

The study locale is in Cabanatuan City, a component city of the province of Nueva Ecija, situated in the heart of Central Luzon which is one of the main islands in the Philippines. It is a landlocked city with 89 barangays and a population of 302,231, as of August 2015, according to the Philippine Statistics Authority (Figure 1).

\section{Study Design}

The study is both qualitative and quantitative in design. The quantitative aspect involved the use of Checklist of Disaster Preparedness while the qualitative part involved the description and determination of effectiveness through the use of observation, interview and analysis of the data observed. Furthermore, the

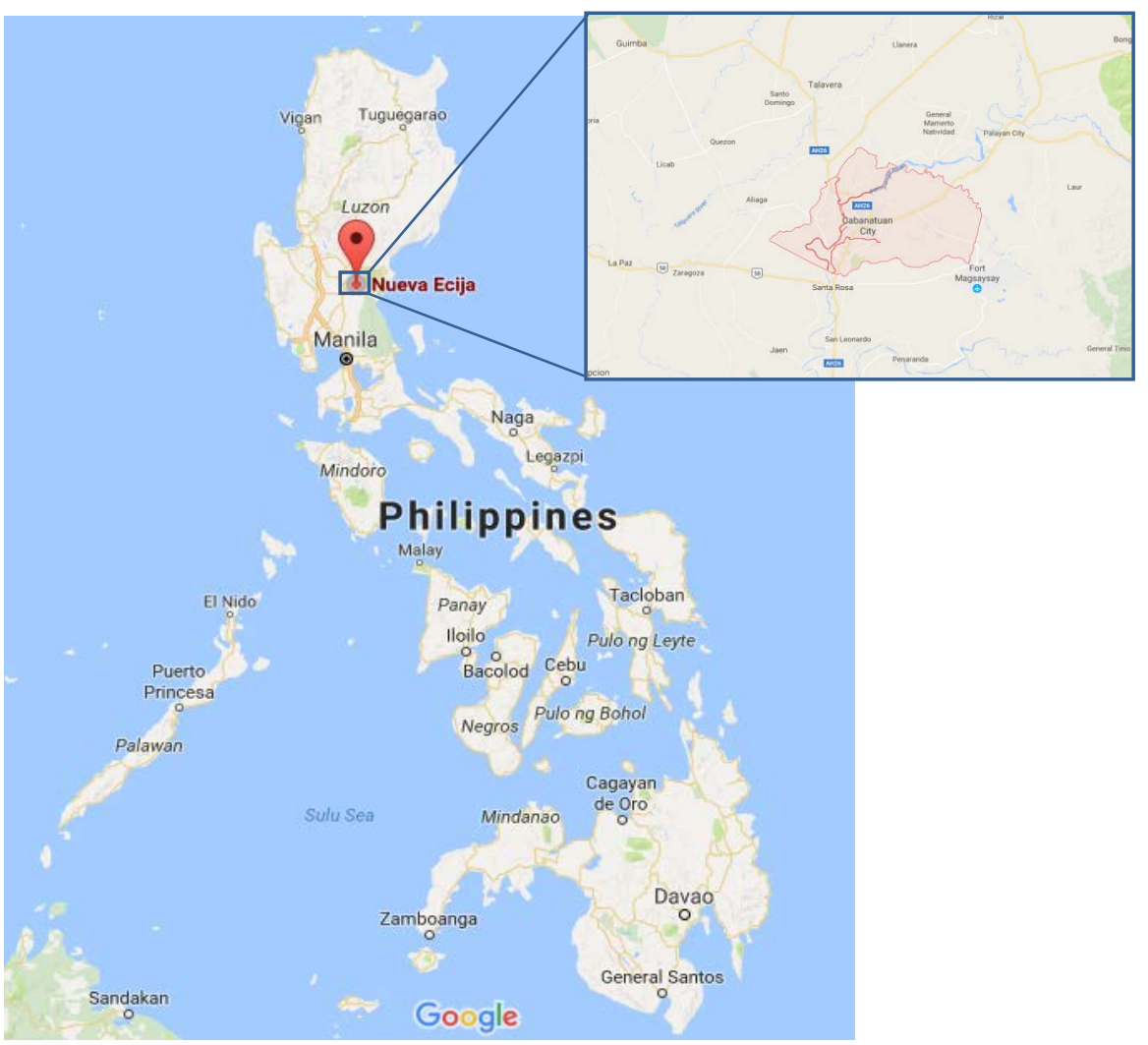

Figure 1. Location of Cabanatuan City. Source: Google Maps. 2017. 
qualitative side of the study focused on describing the how and why of the subject of inquiry using the Goal Model, objectives, and the policies cited. While the quantitative side highlights the measurement of the effectiveness of the BDRRMCs through the relative value of its components, the four thematic areas.

Provided on the checklist are the four thematic areas. Prevention and Mitigation were given 35 points, Preparedness has 30 points, Response has 20, and 15 points was apportioned to Rehabilitation and Recovery. Each thematic area has supporting activities with corresponding points that would meet the objectives set in this study. The point system would be all or nothing. Every maximum point specified is based on the weight or importance of the activity. The first two thematic areas were given large points to satisfy the provisions of the laws and policies cited earlier, the NDRRMF, and NDRRMP. The points from the four thematic areas are totaled using the Microsoft Excel to derive the effectiveness. Thus, the Effectiveness Index yielded the following Score and its Verbal Description, to wit;

\begin{tabular}{cc}
\hline Verbal Description & Score \\
\hline Most Effective: & $91 \%-100 \%$ \\
Much Effective: & $81 \%-90 \%$ \\
Effective: & $71 \%-80 \%$ \\
Least Effective: & $51 \%-70 \%$ \\
Ineffective: & $0 \%-50 \%$ \\
\hline
\end{tabular}

\section{Respondents}

The respondent-barangays are the flood-prone barangays of Cabanatuan City. The flood-prone barangays were selected based on the information gathered from the Cabanatuan City Disaster Risk Reduction and Management Office (CDRRMO). According to the CDRRMO, out of 89 barangays in Cabanatuan City, thirty nine (39) are high risk to flooding, seventeen (17) are medium risk, and the rest are low risk to flooding. Based on a 50\% normal distribution, with $95 \%$ Confidence Level, 15\% Margin of Error, and a population sample of 89 barangays, the sampling yielded a sample size of 30 barangays. They are the following:

\begin{tabular}{lccccc}
\hline 1 & Aduas Centro & 11 & DS Garcia & 21 & Pamaldan \\
2 & Aduas Norte & 12 & Isla & 22 & Rizdelis \\
3 & Aduas Sur & 13 & Imelda & 23 & San Josef Norte \\
4 & Bagong Sikat & 14 & Kapt Pepe & 24 & San Josef Sur \\
5 & Barrera & 15 & Mabini Homesite & 25 & San Juan Accfa \\
6 & Bonifacio & 16 & Matadero & 26 & San Roque Sur \\
7 & Calawagan & 17 & MS Garcia & 27 & Sta Arcadia \\
8 & Caudillo & 18 & Nabao & 28 & Sto Nino \\
9 & Communal & 19 & Pagas & 29 & Talipapa \\
10 & Daan Sarile & 20 & Palagay & 30 & Valdefuente \\
\hline
\end{tabular}


These barangays are high-risks and medium-risk in terms of flooding in the city. And they are the barangays that are easily affected of Pampanga River runoffs, which is the major cause of flooding in the city.

The respondents of the study were seventeen (17) Barangay Captains and thirteen (13) Barangay Secretaries. The Barangay Captain, as chief executive, is the one enforcing laws and ordinances which are applicable within the barangay for the general welfare of the community [9]. While the Barangay Secretary, as an appointive barangay official, is the one in charge of all barangay records. Thus, the Chairperson and or the Secretary are the appropriate respondents of this study to ensure validity of the data gathered.

\section{Theoretical Framework}

This study is guided by the principles of Organization Theory. There have been several studies regarding organizations, its functions and systems, which led to organization theories. Önday (2016) and Yang, et al. (2013) cited Zhu (1999) and defined organization theory as, "knowledge systems which study and explain organizational structure, function and operation and organizational group behavior and individual behavior" [10] [11] [12]. Under organization theories is the measure of organizational effectiveness. And one of the earliest models of organizational effectiveness is the Goal Model. Hall (1980) and Henri (2004) referred to Goodman et al. (1977) and stated that Goal Model is a rational model or set of arrangements and assumptions oriented toward the achievement of goals of the organization [13] [14] [15]. Meanwhile, Etzioni (1977) described effectiveness as the degree to which an organization accomplishes its goals or outcome [16]. The focus of this model is exclusively on the end result or output which is the achievement of goals, objectives, and targets [15]. Hence, the measure of effectiveness is the outcome of organizational activities in terms of measurable outputs [17]. This implies that organizational effectiveness is based on quantifiable activities/outcomes as a result of the BDRRMCs observance and implementation of policies.

\section{Research Paradigm}

The figure below shows the research paradigm of this study. It posits that the Organizational Effectiveness is measured by the number of activities fully implemented by the BDRRMC for every thematic area (Figure 2).

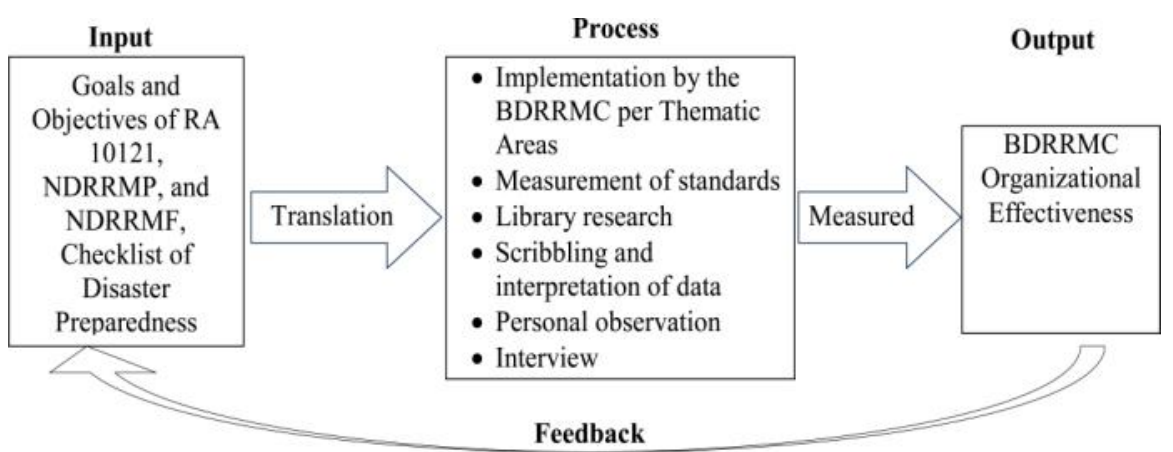

Figure 2. Research paradigm adopted from the presentation of Ismeet Sikka Hersohena, organizational effectiveness, goal approach flow chart. 
As the paradigm shows, box 1 contains the inputs to be used in the study such as RA 10121, NDRRMP, NDRRMF, and Checklist of Disaster Preparedness. The inputs were processed by the implementation of the policies and BDRRMC functions, and as provided by the throughput box above. Thus, would measure the output of this study, the BDRRMC Organizational Effectiveness. The research output shall again form part of the feedback loop, it may be perceived as the trial and testing of the policy. In return, it may be used whether or not to amend or revise the existing policy on disaster management. Also, to create a suitable standard performance/effectiveness measurement on the subject matter. The cycle of input-process-output continues.

\section{Results and Discussion}

Presented on the succeeding pages are the data gathered and their interpretation based on the theory, model, objectives, and policies cited earlier. The legend below will be consistently used on the presentation of the data of the barangays.

\begin{tabular}{|c|c|c|c|}
\hline \multirow{10}{*}{ Legend: } & $\mathrm{A}=$ Aduas Centro & $\mathrm{K}=\mathrm{DS}$ Garcia & $\mathrm{U}=$ Pamaldan \\
\hline & $\mathrm{B}=$ Aduas Norte & $\mathrm{L}=\mathrm{Isla}$ & $\mathrm{V}=$ Rizdelis \\
\hline & $\mathrm{C}=$ Aduas Sur & $\mathrm{M}=$ Imelda & $\mathrm{W}=$ San Josef Norte \\
\hline & $\mathrm{D}=$ Bagong Sikat & $\mathrm{N}=$ Kapt Pepe & $\mathrm{X}=$ San Josef Sur \\
\hline & $\mathrm{E}=$ Barrera & $\mathrm{O}=$ Mabini Homesite & $Y=$ San Juan Accfa \\
\hline & $\mathrm{F}=$ Bonifacio & $\mathrm{P}=$ Matadero & $\mathrm{Z}=$ San Roque Sur \\
\hline & $\mathrm{G}=$ Calawagan & $\mathrm{Q}=$ MS Garcia & $\mathrm{AA}=$ Sta Arcadia \\
\hline & $\mathrm{H}=$ Caudillo & $\mathrm{R}=$ Nabao & $\mathrm{BB}=$ Sto Nino \\
\hline & $\mathrm{I}=$ Communal & $S=$ Pagas & CC $=$ Talipapa \\
\hline & $J=$ Daan Sarile & $\mathrm{T}=$ Palagay & $\mathrm{DD}=$ Valdefuente \\
\hline
\end{tabular}

\section{Disaster Prevention and Mitigation}

The data on Figure 3 shows the scores of the thirty barangays in terms of prevention and mitigation. 9 barangays (30\%) have achieved full 35 points, while 2 barangays got the lowest score of 11 points ( $\mathrm{V}$ and I). The barangays which attained the full score on this thematic area infers their adherence to the objectives of the RA 10121, NDRRMP, and NDRRMF. Also, based on the table, 5 barangays $(16.67 \%)$ have achieved 20 points below (A, I, V, W, CC) which means they have not attained $50 \%$ of the total score on disaster prevention and mitigation. Thus, indicates that prevention and mitigation activities have not been a priority of the barangay. On the positive note, the rest of the barangays attained more than $50 \%$ of the total score in this area, indicating that majority of the barangays have considered to lessen and prevent the adverse effect of flooding in their area.

Of the 6 activities listed under this thematic area, 21 barangays got full points on having plans, policies, and budget. These activities are essentials in disaster management. However, 12 barangays performed poorly on Risk Financing, 3 barangays lack Early Warning System, and 5 barangays do not carry out Risk 


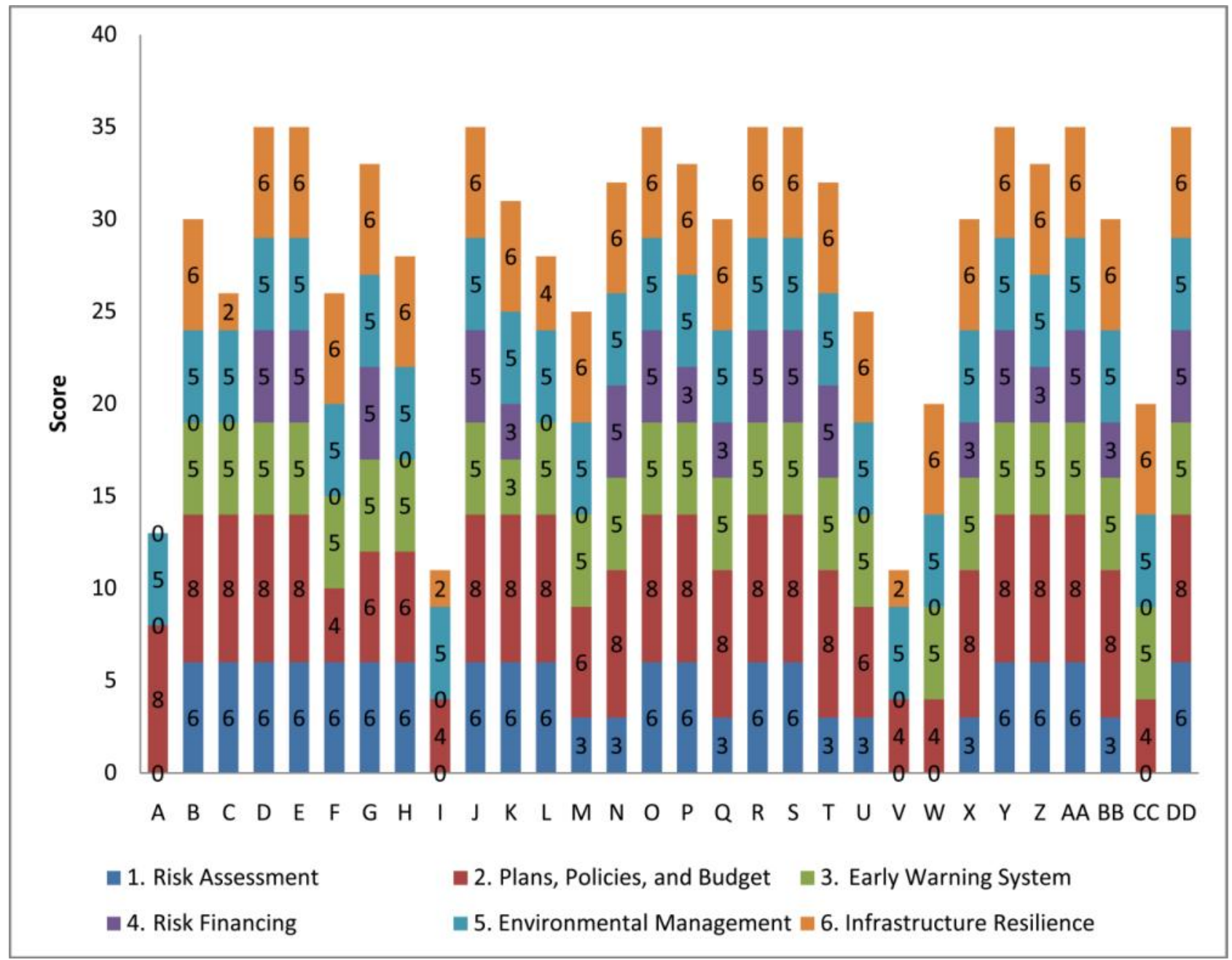

Figure 3. Disaster Prevention and Mitigation.

Assessment activities. Barangays which do not conduct Risk Assessment activities rely only on the budget of their barangays and do not source out fund from financial institutions. And based on the interview and observation of the researcher, Early Warning System and Risk Assessment activities are in place in all barangays but they do not have the clear idea that what they are already doing fall under these activities. This indicates that the policies given to the barangays should be clear and specific in order for the grassroots level to understand and identify the provisions of the law.

By definition, Disaster Mitigation is the "lessening or limitation of the adverse impacts of hazards and related disasters encompassing engineering techniques and hazard-resistant construction as well as improved environmental policies and public awareness" [2]. As shown in the figure, it indicates the priority projects in order to prevent and lessen the impacts of disaster in the community. It depicts enactment and implementation of policies, which is the backbone of disaster management. It focuses on activities which has long term impact on the community. This thematic area is vital on determining whether or not the BDRRMCs are effective on doing what the law mandates. Thus, it is essential in 
the measurement of effectiveness of the BDRRMCs.

However, enactment and implementation of policies requires people's participation. According to Gabriel and Mangahas (2016), "the effectiveness of a public policy rests on effective implementation" [18]. Gabriel and Gutierrez (2017) also pointed out that creation of enabling laws in local government is not enough to create enabling environment. Enabling environment is when people's participation in local legislation provides them sense of ownership of the policies which are useful for effective implementation [17].

\section{Disaster Preparedness}

As indicated on Figure 4, it illustrates the capacity and capability of the BDRRMCs on preparing for any kinds of disaster. This depicts the structure, mechanism, activities, and trainings funded to ensure that the goals on DRRM are achieved.

It is shown on the figure that Barangays $\mathrm{D}$ and $\mathrm{S}$ got the highest score with 27 points, however none of the barangays achieved the full 30 points in disaster preparedness. Nevertheless, 25 barangays achieved more than 50\% (15 points) of the total score in this area depicting that the barangays are equipping themselves even before any disaster strikes, which is one of the key to be effective in disaster management. This shows that they have learned from their experiences and are now prepared for any calamities that may arise.

On the figure, only 5 barangays $(\mathrm{M}, \mathrm{N}, \mathrm{T}, \mathrm{U}, \mathrm{X})$ lack approved plans such as BDRRM Plan, Contingency Plan, and Evacuation Plan. However, none of the 30

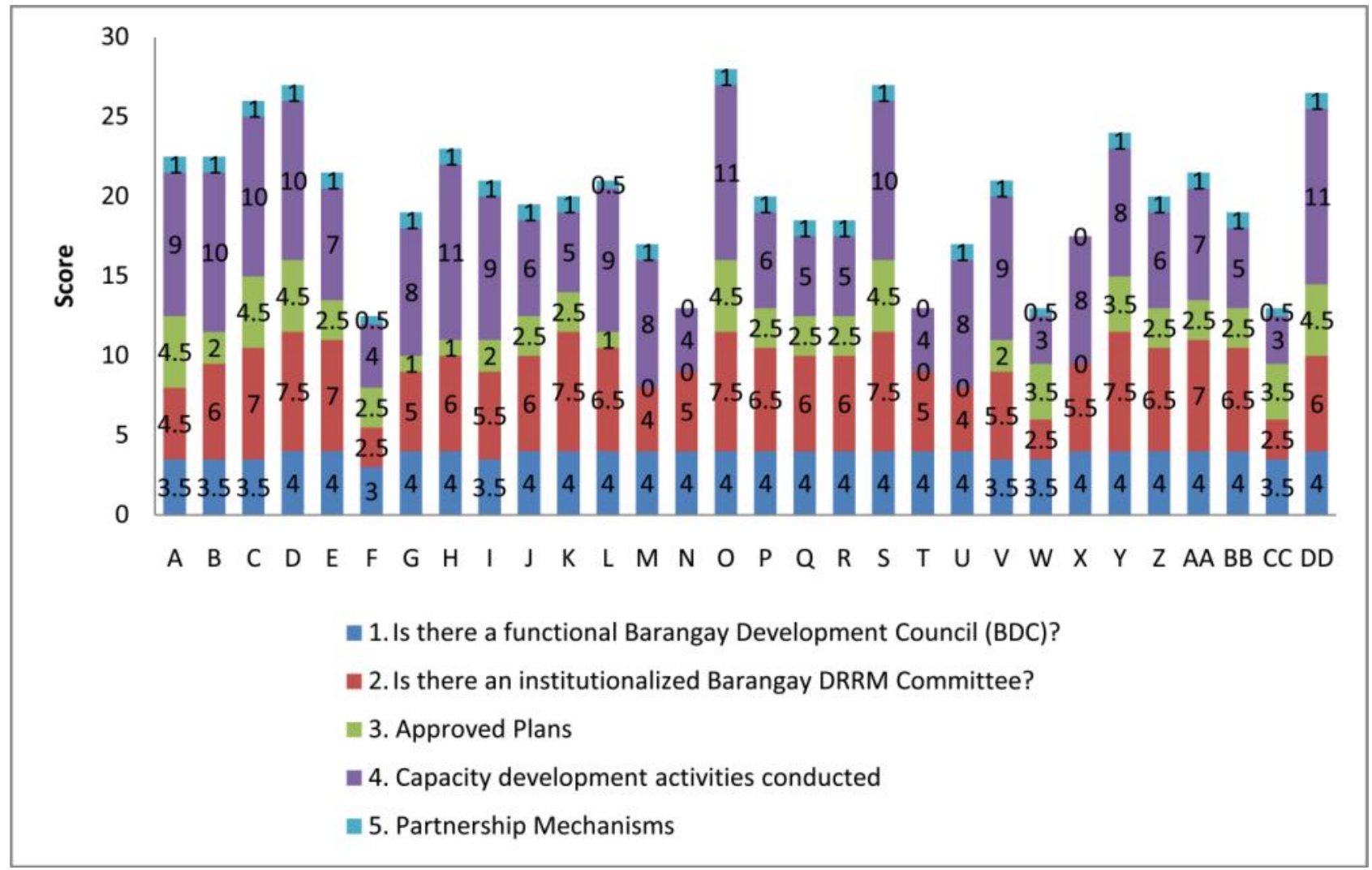

Figure 4. Disaster preparedness. 
barangays attained the maximum points on capacity development activities showing that the barangays need to prioritize and appropriate more funds on trainings and skills development for efficient disaster management and service delivery to the community.

Basically, this thematic area is about community preparation and participation. And participatory approach is the best way to make the community realize how vulnerable they are [19]. Therefore, the BDRRMCs should encourage people's participation to efficiently manage disasters or emergencies which is the essence of the R.A. 10121.

\section{Disaster Response}

Reference [2] provides a detailed definition of Disaster Response. Under this area are the systems on evacuation, relief distribution mechanism, coordination, rapid damage assessment and needs analysis, and on time reporting of the barangay to appropriate agencies. This thematic area presents what the barangay should do during emergencies and calamities.

The data on Figure 5 reveals that only 5 barangays (B, C, H, L, and S) got the full 20 points, 2 barangays $(\mathrm{N}, \mathrm{T})$ got no points at all, but the rest of the barangays (23 barangays) have scored 11 to 17 points or at least more than $50 \%$ of the maximum score for this area. This indicates that the barangays are equipped and are able to display their capability during disaster. Based on its definition and the performance of the BDRRMCs, an effective disaster response is through an effective system of managing a disaster or an emergency. The figure clearly shows that barangays perform well during disaster and they are practicing what they need to do in times of calamities.

As mentioned earlier, effective implementation of the policies and program requires the participation of the community. And each decision and action taken by society makes it more vulnerable or more resilient to disasters [20]. Training

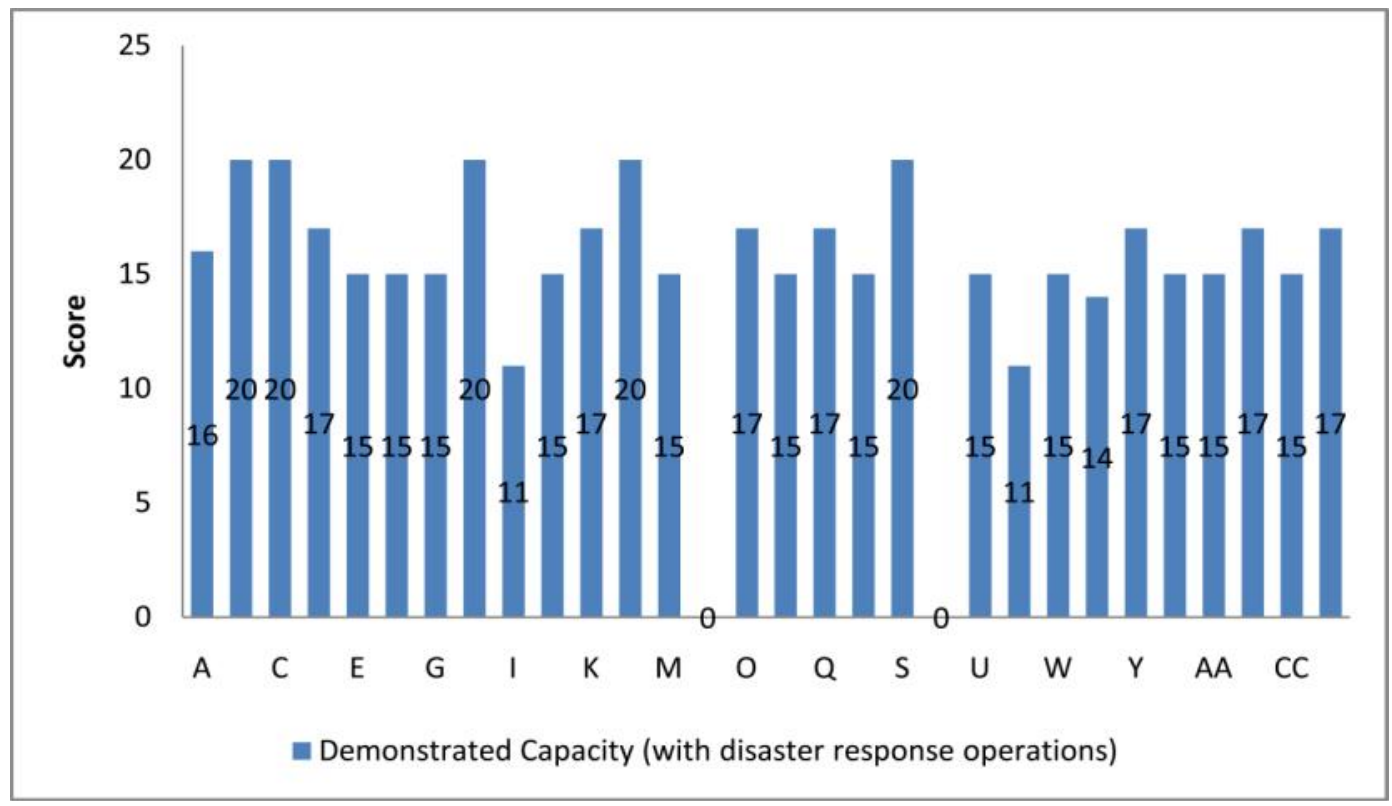

Figure 5. Disaster response. 
on proper response during emergencies would help the barangays to be effective on disaster response. This implies that effective disaster preparedness will result to effective disaster response. Hence, successful response measures are indication of successful preparations [21]. This denotes the importance and interrelatedness of each thematic area with each other. The performance of the barangays on one area will have an effect on their performance on the other areas. This is true in disaster response. If the people know what to do and follow the specified early warning and evacuation procedure (disaster preparedness) the need for emergency services and public assistance in times of disaster would be reduced (disaster response) [Ibid.].

\section{Disaster Rehabilitation and Recovery}

After calamity strikes, a systematic process of preparing for rehabilitation and recovery should be done. This involves post-damage needs assessment (PDNA), restoration activities, and recovery plan to abide by the build-back better principle of the NDRRMP and prevent another disaster to happen. This area involves multi-sectoral and multi-disciplinary approach as it covers estimation and valuation of losses, damages, and needs in agriculture, services, trade, etc. While the BDRRMC is not mainly responsible for the valuation and estimation, it could assist the city/municipal government in identifying the needs of the barangay [21].

As shown in Figure 6, 11 barangays got 15 full points, while only 1 barangay (X) attained no points at all. Based on the table, $1 / 3$ of the sample population attained 8 points below, which is $50 \%$ of the maximum score on rehabilitation and recovery. This suggests that $33 \%$ of the barangays do not have enough activities

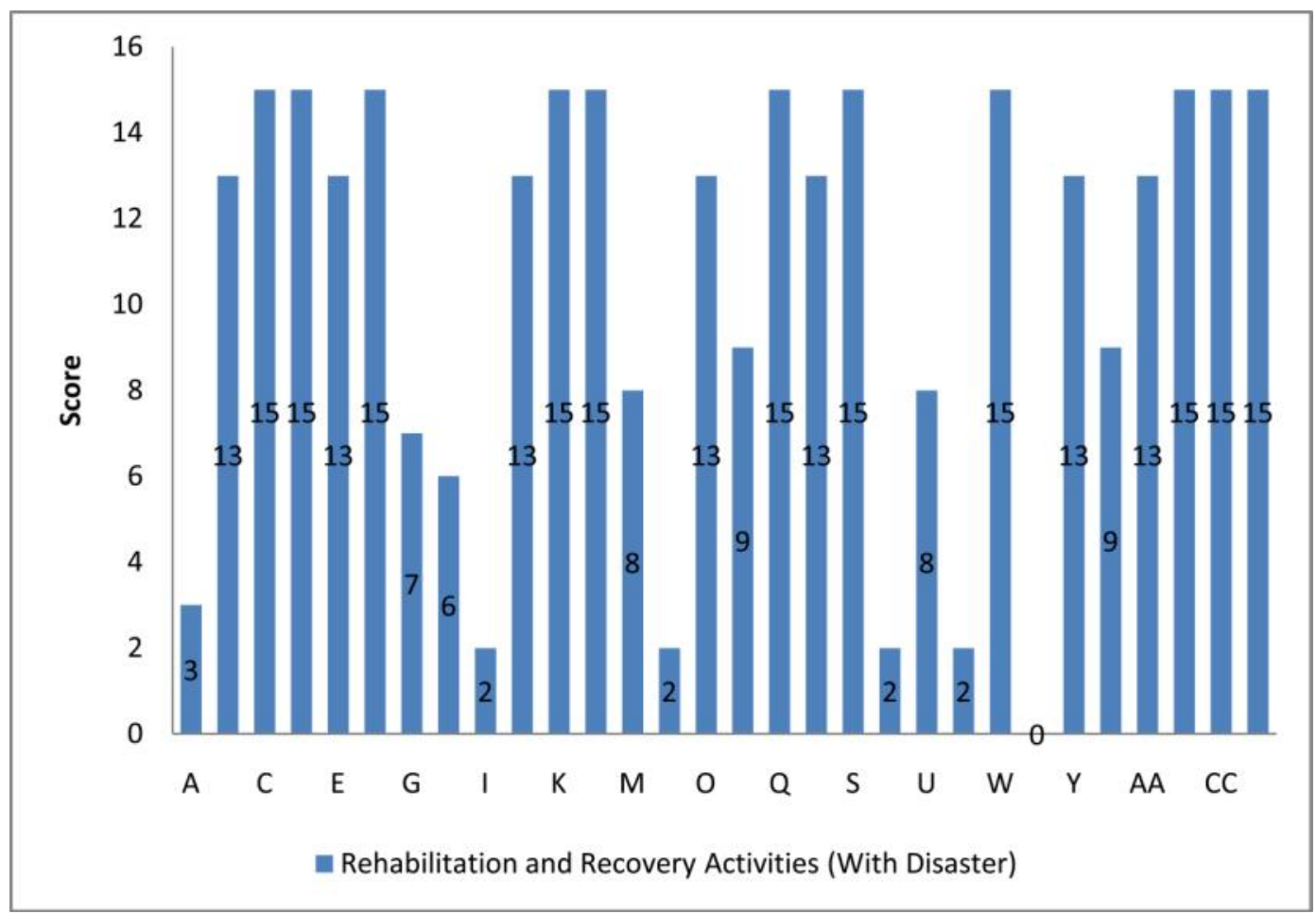

Figure 6. Disaster rehabilitation and recovery. 
on rehabilitation and recovery considering that all of these barangays are prone to flooding. In here, the capacity of the barangays to return to their normal condition is vital in determining whether the preparedness activities of the barangays are enough to make the community resilient. This infers that in rehabilitation and recovery, it will require not only the effectiveness of the BDRRMCs but also the resiliency of the whole community. This will only be achieved if the BDRRMCs are effective in doing the pre-disaster activities that the law required to them to prioritize.

The Effectiveness of the BDRRMCs

The data on Table 1 displays the total scores each barangay has and the verbal

Table 1. Effectiveness of the BDRRMCs.

\begin{tabular}{|c|c|c|}
\hline Barangay & Total Score & Description \\
\hline A & 54.5 & Least Effective \\
\hline B & 85.5 & Much Effective \\
\hline $\mathrm{C}$ & 87 & Much Effective \\
\hline $\mathrm{D}$ & 94 & Most Effective \\
\hline $\mathrm{E}$ & 84.5 & Much Effective \\
\hline $\mathrm{F}$ & 68.5 & Least Effective \\
\hline G & 74 & Effective \\
\hline $\mathrm{H}$ & 77 & Effective \\
\hline I & 45 & Ineffective \\
\hline $\mathrm{J}$ & 82.5 & Much Effective \\
\hline $\mathrm{K}$ & 83 & Much Effective \\
\hline $\mathrm{L}$ & 84 & Much Effective \\
\hline M & 65 & Least Effective \\
\hline $\mathrm{N}$ & 47 & Ineffective \\
\hline $\mathrm{O}$ & 93 & Most Effective \\
\hline $\mathrm{P}$ & 77 & Effective \\
\hline Q & 80.5 & Much Effective \\
\hline $\mathrm{R}$ & 81.5 & Much Effective \\
\hline S & 97 & Most Effective \\
\hline $\mathrm{T}$ & 47 & Ineffective \\
\hline $\mathrm{U}$ & 65 & Least Effective \\
\hline $\mathrm{V}$ & 45 & Ineffective \\
\hline $\mathrm{W}$ & 63 & Least Effective \\
\hline $\mathrm{X}$ & 61.5 & Least Effective \\
\hline $\mathrm{Y}$ & 89 & Much Effective \\
\hline $\mathrm{Z}$ & 77 & Effective \\
\hline AA & 84.5 & Much Effective \\
\hline $\mathrm{BB}$ & 81 & Much Effective \\
\hline $\mathrm{CC}$ & 63 & Least Effective \\
\hline DD & 93.5 & Most Effective \\
\hline
\end{tabular}




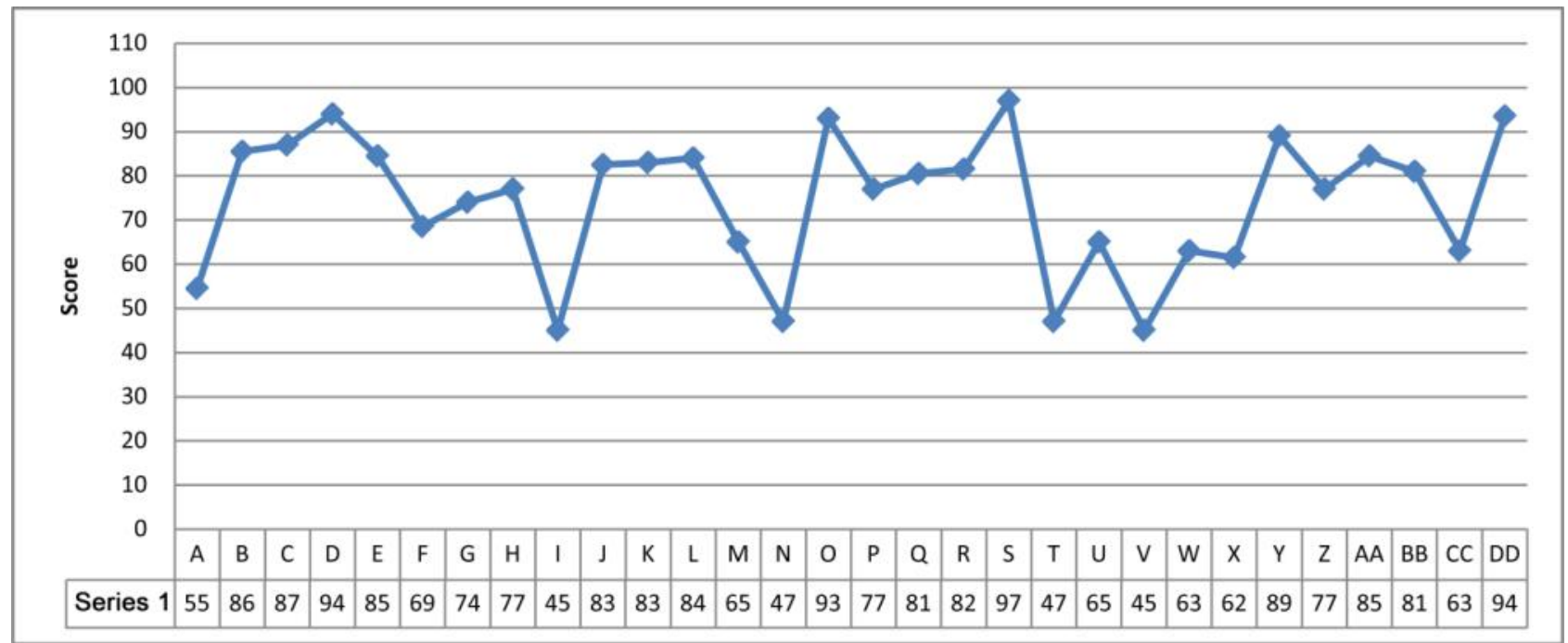

Figure 7. The effectiveness of the BDRRMCs.

description based on the Effectiveness Index used on this study. As presented below, only 4 (13.33\%) barangays (D, O, S, and DD) are described as Most Effective, followed by 11 (36.67\%) barangays which are all defined as Much Effective, another $4(13.33 \%)$ barangays which is described as Effective, 7 barangays (23.33\%) are Least Effective, while 4 barangays (13.33\%) are described as Ineffective.

As indicated on Figure 7, it shows that the highest score were achieved by barangay S (97 points) followed by D (94), DD (93.5) and O (93). Indicating that the results of the four thematic areas discussed earlier clearly identify that the organizational effectiveness of BDRRMCs are achieved if they adhere to the law by implementing all the activities of the four thematic areas.

The Most Effective barangays shown above, specifically barangay S, is consistent in achieving the top scores in all four thematic areas, the same goes with the four Ineffective BDRRMCs wherein. Hence, shows that the effectiveness of the BDRRMCs must be measured as the total of the four thematic areas due to their interrelatedness with each other.

The findings of this study clearly reveal that performance measurement is a vital element in the successful operation of performance management in the public service [22]. The performance of the BDRRMCs in the four thematic areas, as reflected by their organizational effectiveness, definitely ensures the attainment of the goal of the R.A. 10121. And for the policies to be appreciated by the community, sufficient public involvement in local decision making is needed to ensure that primary objectives of the policies reflect community concern [23]. This way the effective implementation and performance of the barangays will be assured.

\section{Conclusion and Recommendations}

\section{Conclusion}

The purpose of this study was to measure the organizational effectiveness of 
the BDRRMCs based on the four thematic areas. And based on the findings, the following conclusions can be drawn from this study. The four thematic areas are interrelated to each other so it really requires the result of each thematic area to assess the effectiveness of the BDRRMCs. The BDRRMCs will be most effective if they are performing their functions. And as prescribed by the law, they should give priorities to all thematic areas, especially prevention and mitigation, and disaster preparedness to achieve the goals and objectives of RA 10121. This way, not only will the barangay be benefitted but the whole community and city as well.

R.A. 10121, NDRRMP, and NDRRMF already provided the essential activities in DRRM. It is up to the people, especially the barangays, how they would appreciate the policies and how they would implement it. But the performance of the barangays on DRRM should be assessed. Rather, there should be a standard on performance and effectiveness measurement to be able to test the policies and somehow revise or amend it based on the performance of the barangay.

\section{Recommendations}

Based on the existing policies and the findings of this study, the researcher arrived to the following recommendations:

1) For the government

a) The researcher recommends the government to establish a standard performance and effectiveness measurement on DRRM per thematic areas, to all levels of the government, specifically to the barangays.

b) To effectively cascade the existing policies on DRRM, the national government should revisit the R.A. 10121 and make its Implementing Rules and Regulations be more detailed, specific, and inclusive for the LGUs to easily appreciate and implement it.

c) The national and local governments should strictly implement the policies regarding DRRM and those integrated in it such as Zoning Ordinance, CLUP, and Climate Change Adaptation Plan.

2) For the Barangay

a) The researcher recommends that the barangay should prioritize Disaster Prevention and Mitigation and Disaster Preparedness activities to effectively and efficiently manage any types of disaster.

b) Since disaster is unpredictable, the barangay should always have plans such as drrm plan, contingency plans, evacuation plan, and recovery plan to properly respond to any types of disaster.

c) The barangay should also encourage peoples' participation to effectively implement the policies on DRRM.

d) The barangay should prioritize DRRM activities in its area to effectively manage any types of disaster.

e) The researcher recommends that the Barangay should adhere to the provisions of the law regarding DRRM to prevent loss of life and property.

3) For Future Researchers

a) The researcher recommends that future researchers on this field should 
conduct study and surveys on the point of views of the citizens or constituents to gauge the effectiveness of the barangays on implementing DRRM. Future researchers might also look at other factors affecting the performance of the barangays in DRRM and derive a different checklist or questionnaires.

b) Future researchers should use different models to measure the organizational effectiveness of the BDRRMCs. Goal Model has its own limitations for it only relies on measuring the goals or the output and requires to meet certain conditions. Future researchers might look into the input, the system or the process to measure the BDRRMCs effectiveness.

\section{References}

[1] National Disaster Risk Reduction and Management Plan (NDRRMP), 2011-2028.

[2] Republic Act 10121, The Philippine Disaster Risk Reduction and Management Act of 2010 .

[3] National Disaster Risk Reduction and Management Framework (NDRRMF), 2011.

[4] Gabriel, A.G. and Manuzon, E.D.P. (2016) Management, Decision Making Styles and Training Preferences of Barangay Officials in Nueva Ecija Philippines. North Asian International Journal of Social Sciences and Humanities, 2, 93-110.

[5] Seal of Good Local Governance: Pagkilala sa kahusayan at katapatan ng Pamahalaang Lokal, DILG Memorandum Circular No. 2014-39, 2014.

[6] Revised Guidelines on the "Gawad KALASAG": Search for Excellence in Disaster Risk Reduction and Management (DRRM) and Humanitarian Assistance 2013, NDRRMC Memorandum Circular No. 02 s. 2013.

[7] Guthrie, J. and English, L. (1997) Performance Information and Program Evaluation in the Australian Public Sector. International Journal of Public Sector Management, 10, 154-164. https://doi.org/10.1108/09513559710166039

[8] Walker, R.M. and Andrews, R. (2013) Local Government Management and Performance: A Review of Evidence. Journal of Public Administration Research and Theory, 25, 101-133.

[9] Republic Act 7160, “The local government code of the Philippines," 1991.

[10] Önday, Ö. (2016) Classical Organization Theory: From Generic Management of Socrates to Bureaucracy of Weber. International Journal of Business and Management Review, 4, 87-105. http://www.eajournals.org/

[11] Yang, C., Liu, H. and Wang, X. (2013) Organization Theories: From Classical to modern. Journal of Applied Science, 13, 4470-4476. https://doi.org/10.3923/jas.2013.4470.4476

[12] Zhu, G. (1999) Organization Theory: History and Genre. Nanjing University Press, Nanjing.

[13] Hall, R.H. (1980) Effectiveness Theory and Organizational Effectiveness. The Journal of Applied Behavioral Science, 16, 536-545. http://journals.sagepub.com/ https://doi.org/10.1177/002188638001600408

[14] Henri, J.-F. (2004) Performance Measurement and Organizational Effectiveness: Bridging the Gap. Managerial Finance, 30, 93-123.

https://doi.org/10.1108/03074350410769137

[15] Goodman, P.S., Pennings, J.M., et al. (1977) New Perspectives on Organizational Effectiveness. Jossey-Bass Publishers, San Francisco, London.

[16] Etzioni, A. (1960) Two Approaches to Organizational Analysis: A Critique and 
Suggestion. Administrative Science Quarterly, 5, 257-258.

https://doi.org/10.2307/2390780

[17] Gabriel, A.G. and Gutierrez M.P. (2017) Praxis in Local Legislative Governance: A Correlation Analysis of Governance Principles and Local Legislative Performance as Measure of Organizational Effectiveness of the Component Cities in Nueva Ecija, Philippines. Asia Pacific Journal of Multidisciplinary Research, 5. http://www.academia.edu/

[18] Gabriel, A.G. and Mangahas, T.L. (2016) Revisiting the Anti-Hazing Law in Selected Higher Education Institutions in Nueva Ecija, Philippines: A Policy Review. Open Access Library Journal, 3, e3177. https://doi.org/10.4236/oalib.1103177

[19] Rahman, K. and Hashi, N.A. (2015) Participatory Earthquake Vulnerability Assessment: A Case Study on Motijhorna Slum. International Conference on $\mathrm{Me}$ chanical Engineering and Renewable Energy (ICMERE2015), Chittagong, Bangladesh, 26-29 November 2015. https://www.academia.edu/

[20] UNISDR (2016) What Is Disaster Risk Reduction? The United Nations Office for Disaster Risk Reduction. https://www.unisdr.org/who-we-are/what-is-drr

[21] Community-Based Disaster Risk Reduction and Management, Basic Instructors' Guide (BIG). OCD-JICA Project Disaster Risk Reduction and Management Capacity Enhancement.

[22] Boyle, R. (2000) Performance Measurement in Local Government. CPMR Discussion Paper 15.

[23] Kloot, L. and Martin, J. (2000) Strategic Performance Management: A Balanced Approach to Performance Management Issues in Local Government. Management Accounting Research, 11, 231-251. http://www.idealibrary.com/

Submit or recommend next manuscript to OALib Journal and we will provide best service for you:

- Publication frequency: Monthly

- 9 subject areas of science, technology and medicine

- Fair and rigorous peer-review system

- Fast publication process

- Article promotion in various social networking sites (LinkedIn, Facebook, Twitter, etc.)

- Maximum dissemination of your research work

Submit Your Paper Online: Click Here to Submit

Or Contact service@oalib.com 